\title{
SELF-CONJUGATE DIFFERENTIAL AND DIFFERENCE OPERATORS ARISING IN THE OPTIMAL CONTROL OF DESCRIPTOR SYSTEMS
}

\author{
VOLKER MEHRMANN AND LENA SCHOLZ
}

\begin{abstract}
We analyze the structure of the linear differential and difference operators associated with the necessary optimality conditions of optimal control problems for descriptor systems in continuous- and discrete-time. It has been shown in [27] that in continuous-time the associated optimality system is a self-conjugate operator associated with a self-adjoint pair of coefficient matrices and we show that the same is true in the discrete-time setting. We also extend these results to the case of higher order systems. Finally, we discuss how to turn higher order systems with this structure into first order systems with the same structure.
\end{abstract}

Mathematics subject classification (2010): 93C05, 93C55, 93C15, 65L80, 49K15, 34H05.

Keywords and phrases: Differential-algebraic equation, self-conjugate difference operator, self-adjoint pair, discrete-time optimal control, necessary optimality condition, congruence transformation, higher order systems.

\section{REFERENCES}

[1] C. D. Ahlbrandt And A. C. Peterson, Discrete Hamiltonian Systems, Kluwer Academic Publisher, 1996.

[2] A. BACKES, Extremalbedingungen für Optimierungs-Probleme mit Algebro-Differentialgleichungen, PhD thesis, Institut für Mathematik, Humboldt-Universität zu Berlin, Berlin, Germany, 2006.

[3] J. T. BETTS, Path constrained trajectory optimization using sparse sequential quadratic programming, J. Guidance Control Dyn., 16: 59-68, 1993.

[4] J. T. Betts, M. J. CARTER, And W. P. HufFman, Software for nonlinear optimization, Mathematics and Engineering Analysis Library Report MEA-LR-83 R1, Boeing Information and Support Services, Seattle, USA, 1997.

[5] L. T. BIEGLER, Optimization strategies for complex process models, Adv. in Chem. Eng., 18: 197$256,1992$.

[6] K. Bobinyec, S. L. Campbell, And P. Kunkel, Maximally reduced observers for linear time varying DAEs, In Proc. IEEE Multi-Conference on Systems and Control, Denver, 2011, pages 13731378, 2011.

[7] H. G. Bock, M. M. Diehl, D. B. Leineweber, And J. P. SCHLÖDER, A direct multiple shooting method for real-time optimization of nonlinear DAE processes, In Nonlinear model predictive control, Ascona, 1998, volume 26 of Progr. Systems Control Theory, pages 245-267, Basel, 2000, Birkhäuser.

[8] K. E. BRenan, S. L. Campbell, And L. R. Petzold, Numerical Solution of Initial-Value Problems in Differential Algebraic Equations, SIAM Publications, Philadelphia, PA, 2nd edition, 1996.

[9] T. BRÜLL, Existence and uniqueness of solutions of linear variable coefficient discrete-time descriptor systems, Linear Algebra Appl., 431: 247-265, 2009.

[10] T. BRÜLL, Explicit solutions of regular linear discrete-time descriptor systems with constant coefficients, Elec. J. Linear Algebra, 18: 317-338, 2009.

[11] R. Byers, D. S. Mackey, V. Mehrmann, and H. Xu, Symplectic, BVD, and palindromic approaches to discrete-time control problems, In P. Petkov and N. Christov, editors, Collection of Papers Dedicated to the 60-th Anniversary of Mihail Konstantinov, pages 81-102, Rodina, Publications, Sofia, Bulgaria, 2009. 
[12] R. Byers, V. Mehrmann, AND H. XU, A structured staircase algorithm for skewsymmetric/symmetric pencils, Electr. Trans. Num. Anal., 26: 1-33, 2007.

[13] R. Byers, V. Mehrmann, And H. Xu, Trimmed linearization for structured matrix polynomials, Linear Algebra Appl., 429: 2373-2400, 2008.

[14] J. W. Demmel AND B. K^̊gSTRÖM, The generalized Schur decomposition of an arbitrary pencil $\lambda A-B$, Part I, ACM Trans. Math. Software, 19: 160-174, 1993.

[15] J. W. Demmel And B. KÅgSTRÖM, The generalized Schur decomposition of an arbitrary pencil $\lambda A-B$, Part II, ACM Trans. Math. Software, 19: 185-201, 1993.

[16] F. R. Gantmacher, The Theory of Matrices II, Chelsea Publishing Company, New York, NY, 1959.

[17] G. H. Golub and C. F. Van Loan, Matrix Computations, The Johns Hopkins University Press, Baltimore, MD, 3rd edition, 1996.

[18] W. W. Hager, Runge-Kutta methods in optimal control and the transformed adjoint system, Numer. Math., 87: 247-282, 2000.

[19] E. Hairer And G. Wanner, Solving Ordinary Differential Equations II: Stiff and DifferentialAlgebraic Problems, Springer-Verlag, Berlin, Germany, 2nd edition, 1996.

[20] R. A. Horn AND V. V. SERGEICHUK, Canonical forms for complex matrix congruence and $*$ congruence, Linear Algebra Appl., 416: 1010-1032, 2006.

[21] W. G. Kelley and A. C. Peterson, Difference equations: An introduction with applications, Academic Press, San Diego, CA, USA, 2001.

[22] V. KUCERA, The structure and properties of time-optimal discrete linear control, IEEE Trans. Automatic Control, 16: 375-377, 1971.

[23] P. Kunkel And V. Mehrmann, Differential-Algebraic Equations. Analysis and Numerical Solution, EMS Publishing House, Zürich, Switzerland, 2006.

[24] P. Kunkel and V. Mehrmann, Optimal control for unstructured nonlinear differential-algebraic equations of arbitrary index, Math. Control, Signals, Sys., 20: 227-269, 2008.

[25] P. Kunkel And V. Mehrmann, Formal adjoints of linear DAE operators and their role in optimal control, Electr. J. Lin. Alg., 22: 672-693, 2011.

[26] P. Kunkel, V. Mehrmann, And W. Rath, Analysis and numerical solution of control problems in descriptor form, Math. Control, Signals, Sys., 14: 29-61, 2001.

[27] P. Kunkel, V. Mehrmann, And L. Scholz, Self-adjoint differential-algebraic equations Appeared electronically in Mathematics of Control, Signals and Systems, 2013. DOI: 10.1007/s00498013-0109-3.

P. Kunkel, V. Mehrmann And L. Scholz, Self-adjoint differential-algebraic equations. Mathematics of Control, Signals, and Systems, 26 (1): 47-76, 2014.

[28] G. A. KURINA, Linear-quadratic discrete optimal control problems for descriptor systems in Hilbert space, J. Dynam. Control Systems, 10: 365-375, 2004.

[29] G. A. KURINA AND R. MÄRZ, On linear-quadratic optimal control problems for time-varying descriptor systems, SIAM J. Cont. Optim., 42: 2062-2077, 2004.

[30] H. KwakernaAK And R. Sivan, Linear Optimal Control Systems. Wiley-Interscience, New York, 1972.

[31] D. S. Mackey, N. Mackey, C. Mehl, And V. Mehrmann, Structured polynomial eigenvalue problems: Good vibrations from good linearizations, SIAM J. Matr. Anal. Appl., 28: 1029-1051, 2006.

[32] D. S. Mackey, N. Mackey, C. Mehl, and V. Mehrmann, Smith forms of palindromic matrix polynomials, Electr. J. Lin. Alg., 22: 53-91, 2011.

[33] D. S. Mackey, N. Mackey, C. Mehl, and V. Mehrmann, Jordan structures of alternating matrix polynomials, Linear Algebra Appl., 432: 867-891, 2010.

[34] V. Mehrmann, The Autonomous Linear Quadratic Control Problem, Springer-Verlag, Berlin, Germany, 1991.

[35] V. Mehrmann and D. Watkins, Polynomial eigenvalue problems with Hamiltonian structure, Electr. Trans. Num. Anal., 13: 106-113, 2002.

[36] J. W. Polderman And J. C. Willems, Introduction to Mathematical Systems Theory: A Behavioural Approach, Springer-Verlag, New York, NY, 1998.

[37] R. C. ThOMPSOn, Pencils of complex and real symmetric and skew matrices, Linear Algebra Appl., 147: 323-371, 1991. 
[38] P. VAN DOOREN, The computation of Kronecker's canonical form of a singular pencil, Linear Algebra Appl., 27: 103-141, 1979.

[39] L. WUNDERLICH,Analysis and Numerical Solution of Structured and Switched Differential-Algebraic Systems, Phd thesis, Institut für Mathematik, Technische Universität Berlin, September 2008. 